\title{
Co-digestion and model simulations of source separated municipal organic waste with cattle manure under batch and continuously stirred tank reactors
}

Tsapekos, Panagiotis; Kougias, Panagiotis ; Kuthiala, Sidhant; Angelidaki, Irini

\section{Published in:}

Energy Conversion and Management

Link to article, DOI:

10.1016/j.enconman.2018.01.002

Publication date:

2018

Document Version

Peer reviewed version

Link back to DTU Orbit

Citation (APA):

Tsapekos, P., Kougias, P., Kuthiala, S., \& Angelidaki, I. (2018). Co-digestion and model simulations of source separated municipal organic waste with cattle manure under batch and continuously stirred tank reactors. Energy Conversion and Management, 159, 1-6. https://doi.org/10.1016/j.enconman.2018.01.002

\section{General rights}

Copyright and moral rights for the publications made accessible in the public portal are retained by the authors and/or other copyright owners and it is a condition of accessing publications that users recognise and abide by the legal requirements associated with these rights.

- Users may download and print one copy of any publication from the public portal for the purpose of private study or research.

- You may not further distribute the material or use it for any profit-making activity or commercial gain

- You may freely distribute the URL identifying the publication in the public portal 

Co-digestion and model simulations of source

$12{ }^{*}$ Corresponding author: Panagiotis G. Kougias, Department of Environmental

13 Engineering, Technical University of Denmark, Bld 113, 2800 Lyngby, Denmark.

14 E-mail address: panak@env.dtu.dk, Tel.: +45 45251454 


\section{Abstract}

16 This study investigates the co-digestion of source separated municipal organic waste

17 (SSMOW), pretreated using a biopulper, and cattle manure both in batch and

18 continuous stirred tank reactors. The optimum co-digestion feeding mixture was

19 consisted of $90 \%$ SSMOW and $10 \%$ cattle manure on organic matter basis, yielding 443

$20 \mathrm{mLCH}_{4} / \mathrm{gVS}$. The high performance of the co-digestion was explained by the fact that

21 the efficient pulping pretreatment boosted the methane production from SSMOW and

22 that the added livestock slurry provided the buffer capacity to avoid inhibition occurred

23 by intermediates' accumulation. Moreover, batch assays focused on the effect of

24 inoculum to substrate ratio (ISR) were performed. Results showed that the reduction of

25 ISR had slight impact on extending the lag phase, without affecting the rest kinetic

26 parameters. The efficiency of the co-digestion process in continuously fed reactor was

27 comparable with the results obtained from the batch assay (i.e. $<95 \%$ of the maximum

28 expected value). Finally, the outputs from an applied mathematical model were in good

29 agreement with the experimental data obtained from the continuous reactor operation,

30 demonstrating that the BioModel can serve as a reliable tool to predict the process

31 performance under real-scale conditions.

\section{Keywords}

34 Source separated municipal organic waste; anaerobic digestion; methane; kinetics;

35 modeling

\section{Introduction}

Anaerobic digestion (AD) of source separated municipal organic waste (SSMOW) is 
considered as a competitive to the traditional (e.g. composting, landfilling, incineration) waste management solution as the organic matter is efficiently degraded producing bioenergy and also, biofertilizer [1,2]. In terms of bioenergy production, SSMOW can ensure high biogas yielding operation [3-5]. Specifically, the presence of soluble carbohydrates, proteins and lipids derived from the kitchen waste residues [6] settles degradable fractions (e.g. plastics) can be also found, as impurities. Thus, a wellperforming separation step can increase process efficiency by initially discarding the non-degradable materials and subsequently, a suitable pretreatment method can boost the deconstruction of previously intact organic matter [7-9]. In industrial perspective, it was previously shown that the integration of two rather dissociated processes into a single and straightforward step is able to remarkably enhance the AD sustainability $52[10]$. can combine these two steps namely separation and pretreatment steps that are needed prior to $\mathrm{AD}$ of SSMOW, into a single process. A biopulper can separate the degradable organic matter and sort-out the non-degradable that can be subsequently recycled, reused or recovered [11]. In addition, the installed milling machinery assists the pretreatment of organic matter improving the biodegradability of SSMOW. In fact, a previous study demonstrated that the pretreatment of SSMOW with pulping technology,

60 led to more than $390 \mathrm{mLCH}_{4} / \mathrm{gVS}$ under different reactor configurations (i.e. batch

61 assays, fed-batch and continuous stirred tank reactors (CSTR)) [5]. 
top of this, the AD process is prone to be inhibited at increased organic loads [1]. Thus,

64 it is crucial to ensure high bioenergy output avoiding risks of acidification incidents and indeed, co-digestion can serve as a potential solution to such inhibition problems. More specifically, cattle slurry is able to increase the $\mathrm{pH}$ towards higher levels and hinder reactor's acidification due rapid volatile fatty acids (VFA) accumulation [12]. In addition, various hydrolytic and fermentative microbes which accelerate the disintegration process are already present in the livestock manure. So, the dissimilar biochemical characteristics of SSMOW and manure substrates can be combined to create a proper feedstock mixture. Furthermore, the usage of livestock slurries into the biogas sector is promoted by the policy-makers by the granted subsidies as mean to solve the manure treatment problem through $\mathrm{AD}$ [13]. Thus, co-digestion strategies using livestock manures are highly exploited.

However, the chemical composition of both substrates is not consistent but is strongly dependent on different parameters, which will in turn affect the final methane productivity. For instance, the major origin of SSMOW can influence positively (e.g. food residues) or negatively (e.g. green waste) the final bioenergy output [14]. On the other hand, nutritional feedstock composition, moisture content, animal species and growth stage are among the parameters that markedly affect manure's biogas productivity [15]. Hence, a universal feeding recipe for the biogas plants is not possible and thus, the optimum feedstock composition should always be independently examined within the framework of co-digestion applications.

Apart from the optimum co-digestion mixture, other kinetic parameters of the $\mathrm{AD}$ process are equally important and should be evaluated. For example, the achievement of a rapid and efficient disintegration of organic matter is assigned to the ratio between 
87 added feedstock and active biomass [16]. Indeed, organic overload inhibits the methanogenic community due to VFA accumulation and over-acidification [17]. Thus, kinetic parameters such as lag phase, hydrolysis and methane rate are influenced by the inoculum to substrate ratio (ISR) [18]. The imbalance between rapid hydrolysisacidification and slow methanogenesis causes organic overload to the archaeal species which could not fully utilise the fed substrate [19]. Hence, it is crucial to secure an efficient feeding strategy to avoid toxicity that can eliminate the methanogenic activity. Furthermore, operational parameters (e.g. reactor's configuration) play an important role towards co-digestion process optimisation. For instance, batch reactors can efficiently provide information about the duration of lag phase, maximum biogas yield, methane and hydrolysis rate. In contrast, CSTR are more appropriate to examine issues as microbiome's acclimatization at long term operation. Experiments are laborious and time consuming and therefore can only cover few experimental conditions. On the contrary, the outcome of both lab-scale reactor set-ups after data interpretation can be

101 extremely useful as input for modeling simulations in order to expand testing at various 102 conditions, and thereby improve the understanding of the AD system. Specifically, 103 reliable mathematical models can reveal in advance the bottlenecks that limit the methane production (e.g. lag phase, substrates inhibition etc.) and highlight the operational conditions (e.g. hydraulic retention time, organic loading rate) that optimise

106 process efficiency [20]. Hence, through reliable simulation outputs, the application of

107 SSMOW for AD can be generalised in the direction of stable and high-yielding biogas 108 production.

109 The aim of the present work was to provide a comprehensive research on 110 exploitation of SSMOW as a major influent substrate for biogas digesters and to 
111 generate a dataset based on continuous reactor operation monitoring that would be used

112 as input for mathematical modeling. Thus, mono- and co-digestion batch assays using

113 SSMOW, pretreated using a biopulper, and cattle manure as the co-substrate were

114 initially conducted. A subsequent batch set was performed to evaluate the kinetics of the

115 most promising feeding mixture and to identify potential problems related to process

116 inhibition at different ISR. Moreover, a continuously fed digester was set up to monitor

117 and evaluate further the effect of the co-digestion process. Finally, a mathematic model

118 (BioModel) was used to simulate the co-digestion process and validate the accuracy of

119 the experimental work.

120

\section{Materials and methods}

\subsection{Inoculum}

Thermophilic inoculum was provided by a well performing lab-scale reactor fed with

124 cattle manure. The digestate was sieved to remove the remaining organic matter and

125 stored in thermophilic incubator for 10 days to reduce the background biogas

126 production. The major physicochemical characteristics of the inoculum, after the

127 degassing process, were $\mathrm{pH}$ : 8.36 , Total Solids (TS): $26.70 \pm 0.20 \mathrm{~g} / \mathrm{L}$, Volatile Solids

128 (VS): $17.54 \pm 0.22$ g/L, Chemical Oxygen Demand (COD): $24.78 \pm 1.19 \mathrm{~g} / \mathrm{L}$, Total

129 Kjeldahl Nitrogen (TKN): $2.32 \pm 0.09$ g-TKN/L, Ammonium Nitrogen: $2.06 \pm 0.10$ g-

$130 \mathrm{NH}_{4}^{+} / \mathrm{L}$ and total Volatile Fatty Acids (TVFA): $0.25 \pm 0.05 \mathrm{~g} / \mathrm{L}$.

2.2 Substrates

133 SSMOW of approximately $25 \%(\mathrm{v} / \mathrm{v})$ industrial and $75 \%(\mathrm{v} / \mathrm{v})$ household waste were

134 collected from Gemidan Ecogi A/S after pulping process, as previously described [11]. 
135 In brief, municipal waste is inserted into a pulper equipped with a helical rotor. The

136 rotor agitates to disperse the bio-degradable organic matter without damaging the non-

137 degradable fraction. Subsequently, the two fractions are separated using a perforated

138 plate. Cattle manure was collected from Hashøj biogas plant. The substrates were

139 diluted with tap water to reach the same content of organic matter to prevent pumping,

140 mixing and clogging problems in the lab scale reactors. After dilution and mixing, the

141 substrates were stored in plastic bottles at $-20^{\circ} \mathrm{C}$ until usage. The main chemical

142 characteristics of the prepared substrates are presented in Table 1.

\subsection{AD experiments}

Biochemical Methane Potential (BMP) assays were initially performed based on

146 Angelidaki et al. [21] in order to define the bioenergy production of the used substrates

147 under mono- and co-digestion trials (i.e. 80:20, 60:40, 40:60 and 20:80 on VS basis).

148 Triplicate glass reactors were used, with total and working volume of 547 and $200 \mathrm{~mL}$,

149 respectively. The inoculum represented $80 \%$ of the working volume and the organic

150 load was $2 \mathrm{gVS} / \mathrm{L}$. Prior to incubation, the batch reactors were flushed with pure $\mathrm{N}_{2}$ to

151 replace the remaining oxygen and achieve anaerobic conditions. Subsequently, they

152 were placed in a thermophilic incubator $\left(54 \pm 1^{\circ} \mathrm{C}\right)$. Based on the results from the first

153 BMP test, the optimum mixing ratio of substrates in the feedstock was determined.

154 Then, a second BMP test was set up to examine the effect of ISR on the AD of the used

155 substrates. Specifically, batch co-digestion experiments were established at three

156 different ISR on VS basis (i.e. 0.5, 1.5 and 3.0) keeping the amount of inoculum

157 constant in all batches [22]. Samples for VFA determination and methane content were

158 taken during the incubation period. For both BMP tests, daily manual stirring was 
159 conducted to avoid the creation of dead zones and monitoring of methane production

160 was performed twice a week until cease of methane production was observed $(p<0.05)$.

161 Moreover, a continuously stirred tank reactor (CSTR) with 9.0 L total and 7.5 L

162 working volume was used to examine the AD of the mixed feedstock under continuous

163 mode operation. The reactor was initially filled with the same inoculum as the batch

164 assays and flushed with pure $\mathrm{N}_{2}$ to ensure anaerobic conditions. Based on the results

165 from the BMP tests, the influent feedstock consisted of $90 \%$ SSMOW and $10 \%$ cattle

166 manure, in terms of VS. The hydraulic retention time was set at 15 days by supplying

$167125 \mathrm{~mL}$ of feedstock four times per day using a peristaltic feeding pump. The organic

168 loading rate of the reactor was set to $2.3 \mathrm{gVS} / \mathrm{L} / \mathrm{d}$. Biogas and liquid samples were taken

169 directly from CSTR at a sequence of twice a week to measure methane concentration,

$170 \mathrm{pH}$ and VFA composition. The CSTR was operated at thermophilic conditions $(54 \pm 1$

$171{ }^{\circ} \mathrm{C}$ ) using silicone thermal jacket. The biogas volume was quantified daily with a gas

172 meter based on water displacement principle and the bioenergy production was

173 calculated.

\subsection{Analytical methods}

176 The standard methods for the examination of water and wastewater were followed

177 for TS, VS, $\mathrm{pH}, \mathrm{COD}, \mathrm{NH}_{4}^{+}$and $\mathrm{TKN}$ measurements [23]. The elementary chemical

178 composition was used to define the carbon to nitrogen ratio $(\mathrm{C} / \mathrm{N})$ of both substrates.

179 Gas chromatography (GC-TRACE 1310) equipped with a thermal flame ionisation

180 detector (FID) was used to determine the methane content of all biogas reactors and to

181 quantify the VFA accumulation (GC-TRACE 1300) [5]. The content of micro- and

182 macro- nutrients in both substrates was determined using inductively coupled plasma 
183 with optical emission spectrometry (ICP-OES). All measurements were performed in

184 triplicate samples.

185

186

187

188

\subsection{Computational methods}

The modified Gompertz equation was used to describe the kinetics of the BMP tests:

$$
M(t)=M_{0} \times \exp \left\{-\exp \left[\frac{R_{\max } \times e}{M_{0}}(\lambda-t)+1\right]\right\}
$$

where, $M(t)$ is the produced $\mathrm{CH}_{4}$ yield over time $t(\mathrm{~mL} / \mathrm{gVS}), M_{0}$ stands for the final $\mathrm{CH}_{4}$ yield (mL/gVS), $R_{\text {max }}$ is the maximum $\mathrm{CH}_{4}$ production rate $(\mathrm{mL} / \mathrm{gVS} / \mathrm{d}), \lambda$ represents the lag phase (day) an $e$ is Euler's constant (2.7183).

The co-digestion of cattle manure with SSMOW under continuous mode operation was evaluated using the extended dynamic bioconversion model (BioModel) [24]. First order kinetics was used to simulate hydrolysis and Monod kinetic was used for the rest AD steps. Moreover, inhibition of VFA to hydrolysis, acetate to acetogenesis, ammonia to methanogenesis and $\mathrm{pH}$ to all $\mathrm{AD}$ steps was examined.

\subsection{Statistical analysis}

Tukey post hoc test $(p<0.05)$ and one-way analysis of variance (ANOVA) was followed to determine the statistically significant variations among mono- and codigestion samples using the software Graphpad Prism (Graphpad Software, Inc., San Diego, CA). The prediction accuracy of the regression analyses were evaluated using the coefficient of determination $\left(R^{2}\right)$ and root mean square error (RMSE). 


\section{Results and discussion}

\subsection{Mono- and co-digestion of SSMOW and cattle manure}

The first set of batch assays was conducted to define the maximum methane yield of SSMOW and cattle manure and to reveal the most efficient co-digestion mixture using these substrates (Fig. 1). Among different feedstocks, the usage of cattle manure as a

210 sole substrate was associated with the lowest biomethanation potential (181 \pm 6

$211 \mathrm{~mL} / \mathrm{gVS}$ ). The limited biodegradability is attributed to the presence of biofibers, as a

212 result of the animal nutrition, which are mainly composed of lignin molecules [13]. In

213 contrast to cattle manure, the obtained methane yield using SSMOW was significantly

214 higher $(464 \pm 69 \mathrm{~mL} / \mathrm{gVS}, p<0.05)$. The increased bioenergy production is attributed

215 to both biomass composition (i.e. high lipid and protein content, negligible

216 lignocellulosic biofibers) and applied pulping pretreatment before AD. Indeed,

217 Khoshnevisan et al. [5] found that the mono-digestion of SSMOW pretreated with a

218 biopulper led to similar results $(490 \mathrm{~mL} / \mathrm{gVS})$ under mesophilic conditions and

219 Naroznova et al. [11] found almost the same methane yield (469 mL/gVS) with the 220 present study under thermophilic conditions.

221 With respect to co-digestion experiments, the higher the contribution of SSMOW in 222 the feedstock the higher the methane production. Especially, the highest methane output 223 was produced using $20 \%$ of cattle manure and $80 \%$ of SSMOW on VS basis in the

224 feedstock $(382 \pm 16 \mathrm{~mL} / \mathrm{gVS})$. As expected, the addition of SSMOW in the feedstock

225 boosted the biogas production. The results can be ascribed to two parameters: 1)

226 compositional differences related to the biodegradable organic polymers with dissimilar

227 theoretical BMP value, and 2) significant variation of co-substrates' $\mathrm{C} / \mathrm{N}$ ratio (Table 1).

228 Specifically, SSMOW contained increased amounts of lipids and soluble carbohydrates 
229 that can boost biomethanation compared to the recalcitrant cattle manure [5]. On the

230 contrary, the high content of nitrogen into cattle manure leads to decreased $\mathrm{C} / \mathrm{N}$ ratio.

231 Thus, during co-digestion trials the markedly higher $\mathrm{C} / \mathrm{N}$ of SSMOW increased the

232 overall value. Accordingly, Zhang et al. [12] examined the co-digestion of food waste

233 with cattle manure and concluded that the optimal $\mathrm{C} / \mathrm{N}$ ratio was 15.8 . The findings are

234 in accordance with the present co-digestion experiments where a $\mathrm{C} / \mathrm{N}$ ratio of 16.9 was

235 associated with the highest methane yield. Moreover, the preference for conducting co-

236 digestion strategies instead of using pure substrates is also induced by the micro-

237 nutrients composition. Specifically, livestock slurries can supplement the required trace

238 elements for high enzymatic activity that are occasionally presented in negligible

239 concentrations in SSMOW [5]. For instance, cattle manure can serve as $\mathrm{Mg}^{2+}$ source to

240 stimulate the fermentation process and additionally, decrease $\mathrm{Na}^{+}$toxicity which can be

241 detected in high levels in SSMOW depending on their origin (e.g. food residues)

$242[12,25]$. In accordance, the content of $\mathrm{Mg}^{2+}$ into the cattle manure $(9.5 \mathrm{mg} / \mathrm{gTS})$ was

243 significantly higher compared to SSMOW (1.9 mg/gTS). On the hand, SSMOW had

244 slightly higher content of $\mathrm{Na}^{+}$than manure, 9.5 and $7.3 \mathrm{mg} / \mathrm{gTS}$ respectively. However,

245 the content of $\mathrm{Na}^{+}$was not high to provoke any salinity stress to the microbial cells [26].

246 Furthermore, the addition of livestock slurry can overcome the occasional lack of $\mathrm{Ca}^{2+}$

247 into the SSMOW (i.e. when green waste corresponds to the major fraction), which is

248 mandatory for the growth of methanogenic archaea [27]. Nevertheless, green waste

249 represented only a minor fraction into the used SSMOW and thus, a $\mathrm{Ca}^{2+}$ deficiency

250 was not observed into the biowaste $(19.7 \mathrm{mg} / \mathrm{gTS})$ compared to manure $(23.6 \mathrm{mg} / \mathrm{gTS})$.

251 In order to limit the co-digestion mixtures to only four but at the same time to be

252 able to define the maximum methane output using both substrates, a mathematical 
253 mixture design approach was followed [28]. Linear, quadratic and full cubic equations

254 were used to fit the experimental data from the BMP tests and subsequently, $R^{2}$ and

255 RMSE were used to evaluate the prediction accuracy (Table 2). In fact, the cubic model

256 had the best prediction quality (i.e. highest $R^{2}$, lowest RMSE). The response

257 optimisation using the full cubic model showed that 90\% SSMOW in the feedstock

258 mixture can lead to even higher methane production than the 20:80. While the

259 calculated value (i.e. 10:90) was slightly lower compared to the highest BMP that was

260 obtained at the mono-digestion of SSMOW (i.e. 0:100), these two methane yields did

261 not differ significantly $(p>0.05)$. Hence, a mixture containing $10 \%$ of cattle manure

262 and $90 \%$ of SSMOW was further examined, due to the relatively high methanation and

263 the high interest with respect to the political and economic frame conditions. The

264 selected feedstock composition was used for the second batch assay and subsequently,

265 to the CSTR operation. Additionally, the results from the second BMP test were used to

266 evaluate the full cubic model output.

\subsection{Effect of ISR to the AD of SSMOW with cattle manure}

In the second batch assay, the effect of inoculum to substrate ratio (ISR) was

elucidated. The results indicated that the methane yield of the selected co-digestion

mixture was not affected by the ISR as insignificant statistical differences were detected. Additionally, the average value of the recorded methane yield (443 \pm 8 $\mathrm{mL} / \mathrm{gVS})$ was slightly higher but significantly meaningless $(p>0.05)$ with the predicted value $(419 \mathrm{~mL} / \mathrm{gVS})$, validating the accuracy of the cubic model obtained from the first BMP test.

276 Based on the outcome of linear regression (i.e. high $R^{2}$, low RMSE), the modified 
277 Gompertz equation had high prediction accuracy. Its applicability to predict similar co278 digestion processes has been previously shown [29,30]; and thus, the kinetic analysis

279 was based on the modified Gompertz model. Apart from the values of methane

280 production, the rest kinetic parameters varied markedly upon the different inoculum to

281 substrate content. It was demonstrated that the higher the amount of inoculum the

282 shorter was the lag phase (Table 3 and Fig. 2). The observations are in agreement with

283 studies examining the effect of substrate to inoculum ratio on wastes from

284 municipalities and livestock industry [16,31]. Indeed, high load of substrate in parallel

285 with limited content of active biomass could lead to reactor's acidification and therefore

286 inhibition $[18,22]$. In the present work, the lowest $\mathrm{pH}$ value (i.e. 6.66) was observed

287 during the 3rd incubation day (Fig. 3a) and was directly connected with the

288 accumulation of TVFA (Fig. 3b) which resulted in limited methane production (Fig. 2).

289 Acetate represented the highest portion of produced intermediates, indicating that the

290 initial three steps of AD were efficiently conducted and only the methanogenesis was

291 partially inhibited during the start-up period. However, on day 8 the TVFA levels of

292 batch assays set at ISR of 0.5 were low and on the 12th day the methane production was

293 similar with the rest ISRs. Hence, the intermediates were efficiently consumed by the

294 methanogenic community and the initially observed accumulation did not lead to

295 irreversible inhibition. In a recent study, the methanogenic community was clearly

296 inhibited at low ISR in continuously fed reactors with SSMOW [5]. The inhibition was

297 depicted by accumulation of VFA and especially acetate concentration, drop of $\mathrm{pH}$, and

298 subsequently, extension of lag phase compared to control operation. However, in the

299 present study irreversible inhibition was not detected.

300 Results obtained from the second batch set showed that the decrease of ISR had only 
301 a slight impact on extending the lag phase during the co-digestion of SSMOW with

302 cattle manure. The strong buffer capacity of livestock slurry alleviated the overload of

303 the inoculum that otherwise can occur at low ISR [18].

\subsection{Continuous mode co-digestion of SSMOW and cattle manure}

CSTR operation is better to mimic the co-digestion of SSMOW with cattle manure to real conditions compared to BMP assays. At steady state conditions, the methane yield of the CSTR was relatively high ( $437 \pm 20 \mathrm{~mL} / \mathrm{gVS}$, Fig. $4 \mathrm{a})$ corresponding to $96 \%$ of the maximum expected output based on the results from the second BMP assay.

310 Typically, the methane production of a continuous reactor reaches $70-90 \%$ of the BMP

311 value [32], which highlights the high efficiency of the investigated system. In this context, the reactor did not face any technical challenges and after seven days of operation reached almost the maximum bioenergy production. Moreover, during the

314 second HRT the overall process performance was already stable. During the whole

315 experimental period, the methane content in biogas was rather constant $(65.3 \pm 2.3 \%)$,

$316 \mathrm{pH}$ was stable $(7.65 \pm 0.06)$ and the VFA were efficiently processed by the AD

317 microbiome and were not accumulated (Fig. 4b). Regarding the individual VFAs, acetic

318 and propionic acids were the dominant intermediates during the whole experimental

319 period. Nevertheless, acetic and propionic acid were always significantly lower than the 320 suggested inhibition indicator of 2.4 and $1.8 \mathrm{~g} / \mathrm{L}$ respectively [33]. In addition, the ratio

321 between acetic to propionic acid was always higher than $1.0 \mathrm{~g} / \mathrm{L}$ validating the wellperforming AD process [34].

323 The increased performance of CSTR was in accordance with the simulation outputs, 324 as the BioModel described efficiently both bioenergy production and biochemical 
325 parameters (Fig. 4). Indeed, the BioModel has a wide range of applicability using

326 various organic substrates as crop residues, food waste, cheese waste, livestock slurries,

327 wastewater sludge and SSMOW [5,35,36] and thus, it is reliably designed to simulate

328 efficiently various co-digestion scenarios. In addition, BioModel considers also

329 ammonia inhibition which is a major problem during the AD of either livestock slurries

330 or SSMOW [37]. However, the used substrates were diluted with water in the present

331 study and thus, the concentration of ammonium nitrogen was low. More specifically,

332 the free ammonia was calculated to be less than $0.05 \mathrm{~g} / \mathrm{L}$ at these conditions and on top

333 of this, no inhibition was indicated in the simulation. In parallel, both CSTR monitoring

334 and BioModel simulations showed that the physicochemical parameters (e.g. TVFA

335 accumulation or $\mathrm{pH}$ increase), which are directly connected with ammonia problems,

336 were within optimal range for AD process. To sum up, the overall reactor performance

337 was good as concluded by both experimental and modeling aspects. SSMOW pretreated

338 with biopulper can easily lead to high bioenergy output without instabilities and

339 therefore, it should be highly considered as a primary feedstock for full-scale biogas

340 plants.

341

342

\section{Conclusions}

343 The present study demonstrated that the anaerobic co-digestion of SSMOW with

344 cattle manure is feasible and leads to high methane production. The kinetics of co-

345 digestion showed that high process performance can be achieved independently from

346 the inoculum to substrate ratio. Moreover, the mixed influent feedstock demonstrated

347 increased biodegradation efficiency which was similar at batch assays and continuous

348 reactor operation. Subsequently, the continuously fed reactor process was modelled 
using the BioModel and the results allowed close fit to the experimental measurements.

\section{Acknowledgement}

352 The authors thank the MUDP project "VARGA - VAnd Ressource Genvindings

353 Anlægget' for financial support. Gemidan Ecogi A/S for substrate providing and

354 Hector Garcia for technical assistance are gratefully acknowledged.

\section{References}

[1] Xu F, Li Y, Ge X, Yang L, Li Y. Anaerobic digestion of food waste - challenges and opportunities. Bioresource Technology 2018;247:1047-1058.

[2] Barati MR, Aghbashlo M, Ghanavati H, Tabatabaei M, Sharifi M, Javadirad G, et al. Comprehensive exergy analysis of a gas engine-equipped anaerobic digestion plant producing electricity and biofertilizer from organic fraction of municipal solid waste. Energy Conversion and Management 2017;151:753-63.

[3] Campuzano R, Gonzalez-Martinez S. Characteristics of the organic fraction of municipal solid waste and methane production: A review. Waste Management 2016;54:3-12.

[4] Kumar A, Samadder SR. A review on technological options of waste to energy for effective management of municipal solid waste. Waste Management 2017. doi:10.1016/j.wasman.2017.08.046.

[5] Khoshnevisan B, Tsapekos P, Alvarado-Morales M, Angelidaki I. Process performance and modelling of anaerobic digestion using source-sorted organic household waste. Bioresource Technology 2018;247:486-95.

[6] Loizidou M, Alamanou DG, Sotiropoulos A, Lytras C, Mamma D, Malamis D, et al. Pilot Scale System of Two Horizontal Rotating Bioreactors for Bioethanol Production from Household Food Waste at High Solid Concentrations. Waste and Biomass Valorization 2017;8:1709-19. doi:10.1007/s12649-017-9900-6.

[7] Bernstad A, Malmquist L, Truedsson C, la Cour Jansen J. Need for improvements in physical pretreatment of source-separated household food waste. Waste Management 2013;33:746-54.

[8] Davidsson Å, Gruvberger C, Christensen TH, Hansen TL, Jansen J la C. Methane yield in source-sorted organic fraction of municipal solid waste. Waste Management 2007;27:406-14.

[9] Hansen TL, Jansen J 1 C, Davidsson $\AA$, Christensen TH. Effects of pre-treatment 
400

401

402

403

404

405

406

407

408

409

410

411

412

413

414

415

416

417

418

419

420

421

technologies on quantity and quality of source-sorted municipal organic waste for biogas recovery. Waste Management 2007;27:398-405.

[10] Tsapekos P, Kougias PG, Egelund H, Larsen U, Pedersen J, Trénel P, et al. Improving the energy balance of grass-based anaerobic digestion through harvesting optimisation. Anaerobe 2017;46:131-7.

[11] Naroznova I, Møller J, Larsen B, Scheutz C. Evaluation of a new pulping technology for pre-treating source-separated organic household waste prior to anaerobic digestion. Waste Management 2016;50:65-74.

[12] Zhang C, Xiao G, Peng L, Su H, Tan T. The anaerobic co-digestion of food waste and cattle manure. Bioresource Technology 2013;129:170-6.

[13] Tsapekos P, Kougias PG, Frison A, Raga R, Angelidaki I. Improving methane production from digested manure biofibers by mechanical and thermal alkaline pretreatment. Bioresource Technology 2016;216:545-52. doi:10.1016/j.biortech.2016.05.117.

[14] Fitamo T, Boldrin A, Boe K, Angelidaki I, Scheutz C. Co-digestion of food and garden waste with mixed sludge from wastewater treatment in continuously stirred tank reactors. Bioresource Technology 2016;206:245-54.

[15] Møller HB, Sommer SG, Ahring BK. Methane productivity of manure, straw and solid fractions of manure. Biomass and Bioenergy 2004;26:485-95.

[16] Hobbs SR, Landis AE, Rittmann BE, Young MN, Parameswaran P. Enhancing anaerobic digestion of food waste through biochemical methane potential assays at different substrate: Inoculum ratios. Waste Management 2017.

[17] Matheri AN, Ndiweni SN, Belaid M, Muzenda E, Hubert R. Optimising biogas production from anaerobic co-digestion of chicken manure and organic fraction of municipal solid waste. Renewable and Sustainable Energy Reviews 2017;80:756-64.

[18] Moset V, Al-zohairi N, Møller HB. The impact of inoculum source, inoculum to substrate ratio and sample preservation on methane potential from different substrates. Biomass and Bioenergy 2015;83:474-82.

[19] Gao S, Huang Y, Yang L, Wang H, Zhao M, Xu Z, et al. Evaluation the anaerobic digestion performance of solid residual kitchen waste by $\mathrm{NaHCO} 3$ buffering. Energy Conversion and Management 2015;93:166-74.

[20] Nguyen DD, Chang SW, Jeong SY, Jeung J, Kim S, Guo W, et al. Dry thermophilic semi-continuous anaerobic digestion of food waste: Performance evaluation, modified Gompertz model analysis, and energy balance. Energy Conversion and Management 2016;128:203-10.

[21] Angelidaki I, Alves M, Bolzonella D, Borzacconi L, Campos JL, Guwy AJ, et al. Defining the biomethane potential (BMP) of solid organic wastes and energy crops: a proposed protocol for batch assays. Water Science \& Technology 
[22] Holliger C, Alves M, Andrade D, Angelidaki I, Astals S, Baier U, et al. Towards a standardization of biomethane potential tests. Water Science and Technology 2016;74:2515-22.

[23] APHA. Standard Methods for the Examination of Water and Wastewater, Washington, DC, USA: American Public Health Association; 2005.

[24] Angelidaki I, Ellegaard L, Ahring BK. A comprehensive model of anaerobic bioconversion of complex substrates to biogas. Biotechnology and Bioengineering 1999;63:363-72.

[25] Wu LJ, Kobayashi T, Kuramochi H, Li YY, Xu KQ. Effects of Potassium, Magnesium, Zinc, and Manganese Addition on the Anaerobic Digestion of Deoiled Grease Trap Waste. Arabian Journal for Science and Engineering 2016;41:2417-27.

[26] Chen Y, Cheng JJ, Creamer KS. Inhibition of anaerobic digestion process: a review. Bioresource Technology 2008;99:4044-64.

[27] Jackson-Moss CA, Duncan JR, Cooper DR. The effect of calcium on anaerobic digestion. Biotechnology Letters 1989;11:219-24.

[28] Rahman MA, Møller HB, Saha CK, Alam MM, Wahid R, Feng L. Optimal ratio for anaerobic co-digestion of poultry droppings and lignocellulosic-rich substrates for enhanced biogas production. Energy for Sustainable Development 2017;39:59-66.

[29] Tsapekos P, Kougias PG, Vasileiou SA, Lyberatos G, Angelidaki I. Effect of micro-aeration and inoculum type on the biodegradation of lignocellulosic substrate. Bioresource Technology 2017;225:246-53.

[30] Zhao MX, Ruan WQ. Biogas performance from co-digestion of Taihu algae and kitchen wastes. Energy Conversion and Management 2013;75:21-4.

[31] Yoon YM, Kim SH, Shin K-S, Kim C-H. Effects of Substrate To Inoculum Ratio on the Biochemical Methane Potential of Piggery Slaughterhouse Wastes. Asian Australas J Anim Sci 2014;27:600-7.

[32] Schnürer A, Bohn I, Moestedt J. Protocol for Start-Up and Operation of CSTR Biogas Processes. In: McGenity TJ, Timmis KN, Nogales B, editors. Hydrocarbon and Lipid Microbiology Protocols: Bioproducts, Biofuels, Biocatalysts and Facilitating Tools, Berlin, Heidelberg: Springer Berlin Heidelberg; 2017, p. 171-200.

[33] Franke-Whittle IH, Walter A, Ebner C, Insam H. Investigation into the effect of high concentrations of volatile fatty acids in anaerobic digestion on methanogenic communities. Waste Management 2014;34:2080-9.

[34] Weiland P. Biogas production: Current state and perspectives. Applied Microbiology and Biotechnology 2010;85:849-60. 
461

462

463

464

465

466

467

468

469

470
[35] Kovalovszki A, Alvarado-Morales M, Fotidis IA, Angelidaki I. A systematic methodology to extend the applicability of a bioconversion model for the simulation of various co-digestion scenarios. Bioresource Technology 2017;235:157-66.

[36] Lovato G, Alvarado-Morales M, Kovalovszki A, Peprah M, Kougias PG, Rodrigues JAD, et al. In-situ biogas upgrading process: Modeling and simulations aspects. Bioresource Technology 2017;245:332-41.

[37] Yenigün O, Demirel B. Ammonia inhibition in anaerobic digestion: A review. Process Biochemistry 2013;48:901-11. 
$471 \quad$ Figure captions

472 Fig. 1. Methane yields of mono- and co-digestion tests of cattle manure and SSMOW

473

474 Fig. 2. Cumulative $\mathrm{CH}_{4}$ production as a function of time during the co-digestion of

475 SSMOW with cattle manure at different ISR.

476

477 Fig. 3. $\mathrm{pH}$ change (a) and TVFA accumulation (b) as a function of time during the co478 digestion of SSMOW with cattle manure at different ISR.

479

480 Fig. 4. Experimental data and modelling simulations for bioenergy yield (a) and $\mathrm{pH}$

481 alteration and TVFA accumulation (b) during the co-digestion o of SSMOW with cattle 482 manure in continuous mode operation

483 
485 Table 1. Characteristics of SSMOW and cattle manure

\section{Characteristics}

pH

TS, g/L

VS, g/L

COD, $\mathrm{g} / \mathrm{L}$

TKN, g/L

$\mathrm{NH}_{4}^{+}, \mathrm{g} / \mathrm{L}$

C/N

TVFA, g/L

Acetate, $\mathrm{g} / \mathrm{L}$

Propionate, g/L

Iso-butyrate

Butyrate

Iso-valerate

Valerate
SSMOW

4.05

$40.65 \pm 0.64$

$35.00 \pm 0.67$

$62.34 \pm 1.78$

$1.23 \pm 0.04$

$0.29 \pm 0.04$

$19.01 \pm 0.95$

$1.73 \pm 0.05$

$1.54 \pm 0.05$

$0.06 \pm 0.00$

$0.01 \pm 0.00$

$0.11 \pm 0.01$

$0.01 \pm 0.00$

$0.01 \pm 0.00$
Cattle manure

7.24

$48.25 \pm 0.23$

$35.00 \pm 0.04$

$56.99 \pm 1.63$

$2.46 \pm 0.08$

$1.61 \pm 0.08$

$8.69 \pm 0.43$

$6.73 \pm 0.30$

$4.49 \pm 0.29$

$1.19 \pm 0.08$

$0.16 \pm 0.00$

$0.59 \pm 0.02$

$0.27 \pm 0.08$

$0.05 \pm 0.00$

486 
487 Table 2. Models summary statistics with BMP as response variable and VS share of

488 SSMOW in the feedstock as regressor.

\begin{tabular}{llll} 
Model & Regression equations & $\boldsymbol{R}^{2}$ & $\boldsymbol{R M S E}$ \\
\hline Linear & $\mathrm{BMP}=2.503 \times \mathrm{VS}+204.063$ & 0.956 & 18.45 \\
Quadratic & $\mathrm{BMP}=-0.004 \times \mathrm{VS}^{2}+2.946 \times \mathrm{VS}+198.153$ & 0.958 & 17.91 \\
Cubic & $\mathrm{BMP}=0.001 \times \mathrm{VS}^{3}-0.102 \times \mathrm{VS}^{2}+6.505 \times \mathrm{VS}+182.566$ & 0.996 & 5.42
\end{tabular}

489 
490 Table 3. Parameters of modified Gompertz equation fitting experimental results

491 obtained from the co-digestion of SSMOW with cattle manure at different ISR

\begin{tabular}{rrrr}
\hline & \multicolumn{3}{c}{ ISR } \\
\cline { 2 - 4 } Modified Gompertz equation & $\mathbf{0 . 5}$ & $\mathbf{1 . 5}$ & $\mathbf{3 . 0}$ \\
\hline$\lambda$, days & 3.11 & 2.63 & 1.95 \\
$R_{\max }, \mathrm{mL} / \mathrm{gVS} / \mathrm{d}$ & 90 & 118 & 96 \\
Measured BMP, $\mathrm{mL} / \mathrm{gVS}$ & 444 & 455 & 446 \\
Predicted BMP, $\mathrm{mL} / \mathrm{gVS}$ & 442 & 452 & 438 \\
Difference, $\%$ & 0.5 & 0.7 & 1.9 \\
$R^{2}$ & 0.999 & 0.999 & 0.999 \\
RMSE & 4.19 & 2.38 & 5.54 \\
\hline
\end{tabular}

492 